\title{
PENGARUH PENGGUNAAN VARIASI KONSENTRASI AVICEL PH-101 PADA FORMULA TABLET PREDNISOLONE
}

\author{
Hilda Suherman \\ Sekolah Tinggi Ilmu Kesehatan Harapan Bangsa Purwokerto
}

\begin{abstract}
Abstrak
Prednisolone merupakan obat golongan steroid yang digunakan untuk mengobati beberapa alergi jenis tertentu, kondisi peradangan, gangguan autoimun dan kanker. Kelarutan prednisolone sangat sukar larut dalam air menimbulkan masalah pada proses absorbsi sehingga diperlukan formula yang optimum untuk membentuk tablet Prednisolone yang memenuhi syarat sifat fisik tablet. Tujuan penelitian ini untuk membuat formula optimum dengan kombinasi eksipien laktosa, avicel $\mathrm{pH}-101$, dan amprotab untuk memperoleh tablet prednisolone dengan sifat fisik dan disolusi yang baik.

Tablet prednisolone dibuat 7 formula dengan kombinasi laktosa (A) Avicel PH-101 (B), dan Amprotab (C), Formula I (100\%A); Formula II (100\%B); Formula III (100\%C); Formula IV $(50 \% \mathrm{~A}+50 \% \mathrm{~B})$; Formula V $(50 \% \mathrm{~A}+50 \% \mathrm{C})$; Formula VI $(50 \% \mathrm{~B}+50 \% \mathrm{C})$; Formula VII $(33,33 \% \mathrm{~A}+33,33 \% \mathrm{~B}+33,33 \% \mathrm{C})$ sebanyak 2 batch . Metode pembuatan tablet prednisolone dengan cara cetak langsung. Pengujian tablet prednisolone meliputi sifat fisik tablet keseragaman bobot, keseragaman ukuran, kekerasan, kerapuhan, waktu hancur, serta uji disolusi, dan penetapan kadar.
\end{abstract}

Kata kunci : optimasi formula, tablet, Prednisolone, Simplex Lattice Design.

\begin{abstract}
Prednisolone is a steroid class drug that is used to treat certain types of allergies, inflammatory conditions, autoimmune disorders and cancer. Solubility of prednisolone is very difficult to dissolve in water causing problems in the absorption process so that the optimum formula is needed to form Prednisolone tablets that meet the requirements of the physical properties of tablets. The purpose of this study was to make the optimum formula with a combination of lactose excipients, avicel $\mathrm{pH}-101$, and amprotab to obtain prednisolone tablets with good physical properties and dissolution.

Prednisolone tablets made 7 formulas with a combination of lactose (A) Avicel PH-101 (B), and Amprotab (C), Formula I (100\% A); Formula II (100\% B); Formula III (100\% C); Formula IV $(50 \% A+50 \%$ B); Formula V $(50 \% A+50 \%$ C); Formula VI $(50 \%$ B $+50 \%$ C); Formula VII $(33.33 \% A+33.33 \% B+33.33 \% C)$ in 2 batches. The method of making prednisolone tablets by direct printing. Testing of prednisolone tablets included the physical properties of tablets, weight uniformity, uniformity in size, hardness, friability, disintegration time, and dissolution test, and content determination.
\end{abstract}

Keywords: optimization of formulas, tablets, Prednisolone, Simplex Lattice Design. 


\section{PENDAHULUAN}

Berkembangnya

ilmu

pengetahuan dan teknologi di bidang

farmasi mendorong farmasis

membuat suatu formulasi yang tepat dengan membuat suatu strategi dan desain bentuk sediaan yang acceptable sesuai dengan efek yang diharapkan dan reproducible dari batch ke batch (Voight, 1994).

Teknologi farmasi mencakup semua aspek yang terkait dengan pabrikasi sediaan obat baik bahan aktif obat maupun exipient (bahan tambahan). Kualitas sediaan obat tidak hanya berfokus pada bahan aktif saja, tetapi berkaitan pula dengan pemilihan bahan tambahan yang tepat. Pengembangan eksipien perlu dilakukan baik di tingkat penelitian maupun realisasi pabrikasi di industri yang bertujuan untuk memperbaiki sifat fisika kimia sediaan obat, sehingga diperoleh formula yang optimum dalam ketersediaan farmasetik, ketersediaan hayati dan efek yang dihasilkan (Kurniawan dan Sulaiman, 2009).

Suatu bahan aktif harus melalui tahapan preformulasi dan formulasi. Pada tahap formulasi diperlukan desain dan strategi untuk menghasilkan produk yang berkualitas. Strategi dilakukan melalui optimasi yang terkonsep, baik menggunakan metode factorial design (FD), maupun simplex lattice design (SLD).

Tablet merupakan sediaan obat padat takaran tunggal yang dicetak dari sebuk kering, kristal atau granulat, umumnya dengan penambahan eksipien pada mesin yang sesuai dengan menggunakan suatu tekanan tinggi. Banyak masalah yang muncul dalam formulasi dan pembuatannya, seperti kecepatan alir bahan, daya kompresibilitas, disolusi yang kurang baik, profil disolusi dan masalah inkompatibilitas antara komponenkomponen penyusun sediaan obat (Voight, 1994). Obat dalam bentuk sediaan padat berupa tablet salah satunya adalah Piroksikam.

Prednisolone adalah obat
golongan kortikosteroid yang
berfungsi untuk mengurangi
peradangan dalam beberapa kondisi
medis seperti artitis, asma, kelainan
sistem kekebalan tubuh, kelainan
darah, gangguan paru dan


pernapasan, alergi parah, penyakit persendian dan otot serta penyakit kulit (Dipiro et al., 2008). Prednisolone mempunyai waktu paruh eliminasi yang panjang, sehingga diberikan dengan dosis sekali sehari untuk membantu kepatuhan penderita (Katzung, 1998). Prednisolone termasuk Biopharmaceutic Classification System Class 2 yang memiliki karakteristik kelarutan dalam air rendah, permeabilitas dalam usus tinggi sehingga proses absorbsi cepat tetapi profil disolusinya buruk (Sari, 2004).

Prednisolone termasuk obat dosis rendah dengan dosis lazim 10$20 \mathrm{mg}$ per hari sehingga pemilihan eksipien dan optimasi formula sangat mempengaruhi sifat fisik tablet. Eksipien yang dipilih meliputi laktosa, avicel PH-101, dan amprotab. Laktosa sebagai pengisi untuk memenuhi bobot tablet yang diinginkan, dimana laktosa ini mempunyai sifat alir dan kompaktibilitas yang baik sehingga dapat memperbaiki sifat alir massa serbuk yang dihasilkan. Avicel PH101 (mycrocristaline cellulose) berfungsi sebagai bahan pengikat dengan potensi daya ikat yang kuat, dan Amprotab (Amilum manihot) sebagai penghancur yang merupakan koloida hidrofilik yang mempunyai kapasitas absorbsi yang besar sehingga dalam tablet bahan ini akan mengembang, menjadikan tablet pecah dan hancur.

Optimasi formula tablet prednisolone dilakukan dengan metode optimasi Simplex Lattice Design 3 faktorial, dengan tujuan menentukan proporsi 3 jenis eksipien yaitu laktosa, avicel PH-101, dan amprotab yang optimum (Bolton, 1997). Berdasarkan latar belakang tersebut, maka dilakukan penelitian tentang optimasi formula tablet prednisolone dengan eksipien laktosa, avicel PH-101 dan amprotab dengan metode Simplex Lattice Design 3 faktorial, sehingga diperoleh proporsi masing-masing eksipien yang diharapkan menghasilkan formula dengan profil disolusi dan sifat fisik yang optimum. 


\section{METODOLOGI}

\section{Waktu dan Lokasi Penelitian}

Penelitian ini dilakukan selama 4 bulan di Laboratorium STIKes Harapan Bangsa Purwokerto..

\section{Alat dan Bahan Penelitian}

\section{A. Alat Penelitian}

Alat-alat yang digunakan yaitu seperangkat alat gelas, timbangan digital, mesin cetak tablet single punch, cube mixer, alat uji kekerasan atau hardness tester, alat uji kerapuhan (friability tester), jangka sorong, ayakan mesh 40, stopwatch, dissolution tester, spektrofotometer UVVis (Shimadzu UVmini-1240), dan glass ware.

\section{B. Bahan Penelitian}

Bahan-bahan yang digunakan yaitu prednisolone, Laktosa, Avicel PH-101, Amprotab, Magnesium stearate, Metanol, $\mathrm{HCl}, \mathrm{NaCl}$, dan aquadest.

\section{Rancangan Penelitian}

Penelitian ini termasuk jenis penelitian eksperimental laboratorium meliputi penentuan rancangan formula dengan metode Simplex Lattice Design, pembuatan tablet, pengujian hasil formulasi meliputi uji sifat fisik tablet yaitu keseragaman bobot, keseragaman ukuran, kekerasan, kerapuhan, waktu hancur, serta uji disolusi, keseragaman kadar, dan pemilihan formula optimum berdasarkan diagram Superimpossed counter plot.

Tahapan penelitian ini dirancang sebagai berikut :

1. Penentuan rancangan formula tablet prednisolone dengan eksipien laktosa, avicel, dan amprotab berdasarkan metode Simplex Lattice Design

2. Pembuatan Tablet

3. Uji sifat fisik, uji disolusi dan keseragaman kadar tablet

4. Penentuan formula optimum tablet prednisolone berdasar diagram Superimpossed counter plot.

Variabel yang digunakan dalam penelitian ini yaitu :

\section{a) Variabel Bebas}

\begin{tabular}{lllr}
\multicolumn{1}{c}{ Variabel } & bebas & dalam \\
penelitian ini & adalah \\
perbandingan & & \multicolumn{2}{c}{ konsentrasi }
\end{tabular}


laktosa, avicel pH-101 dan amprotab dalam formulasi tablet prednisolone.

b) Variabel Tergantung

$\begin{array}{lr}\text { Variabel tergantung } \\ \text { dalam penelitian ini } & \text { adalah } \\ \text { sifat fisik tablet } & \text { berupa } \\ \text { keseragaman } & \text { bobot, } \\ \text { keseragaman } & \text { ukuran, } \\ \text { kekerasan, kerapuhan, waktu }\end{array}$

hancur, serta uji disolusi, dan keseragaman kadar.

c) Variabel Terkendali

$$
\text { Variabel terkendali }
$$

dalam penelitian ini adalah metode pembuatan (cetak langsung), ukuran partikel, tekanan kompresi, pencampuran serta bobot tablet.

Tahap penelitian yang dilakukan adalah sebagai berikut :

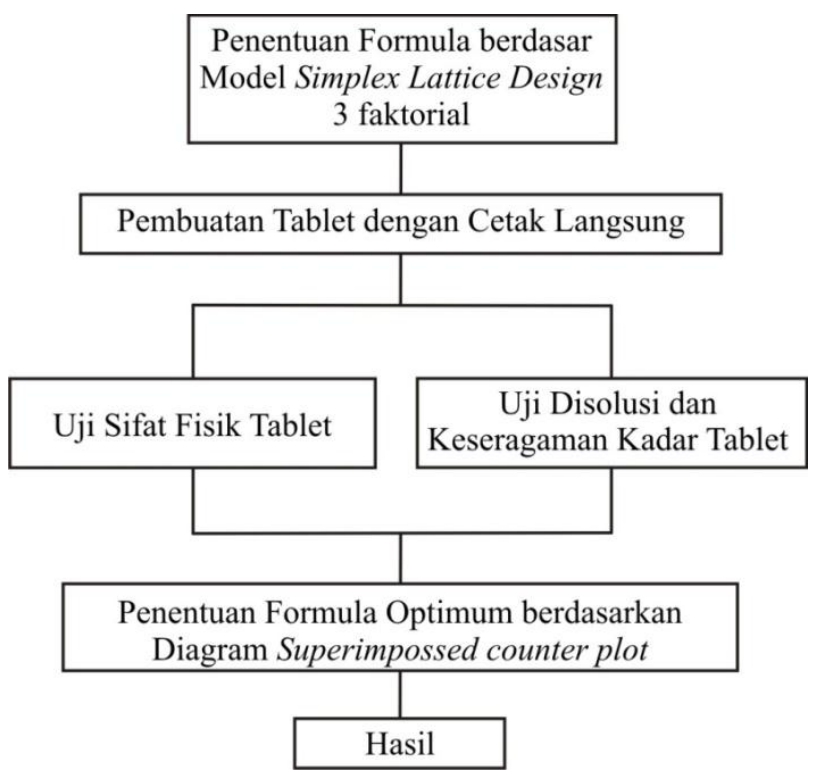

\section{Gambar 7. Skema Penelitian}

\section{Jalannya Penelitian}

\section{Penentuan Formula Tablet}

Prednisolone dengan Metode

Simplex Lattice Design

Penentuan formula dilakukan menggunakan variasi eksipien yaitu Laktosa (komponen A),
Avicel pH-101 (komponen B), dan Amprotab (komponen C) dalam proporsi tertentu.

Formula umum untuk tiap tablet (berat total $=150 \mathrm{mg}$ ) adalah sebagai berikut : 


$$
\begin{array}{ll}
\text { F I } & =100 \% \text { Laktosa } \\
\text { FII } & =100 \% \text { Avicel } \\
\text { F III } & =100 \% \text { Amprotab } \\
\text { F IV } & =\text { campuran 50\% Laktosa }+50 \% \text { Avicel } \\
\text { F V } & =\text { campuran } 50 \% \text { Laktosa }+50 \% \text { Amprotab } \\
\text { F VI } & =\text { campuran } 33,3 \% \text { Laktosa }+33,3 \% \text { Avicel }+33,3 \% \text { Amprotab }
\end{array}
$$

Tabel 2. Formula tablet Prednisolone secara Simplex Lattice Design dengan bobot tablet $150 \mathrm{mg}$.

\begin{tabular}{lcccccc}
\hline Formula & \multicolumn{5}{c}{ Bahan (mg) } & $\begin{array}{c}\text { Bobot } \\
\text { Tablet }\end{array}$ \\
\cline { 2 - 6 } & Piroksikam & $\begin{array}{c}\text { Mg } \\
\text { Stearat }\end{array}$ & Laktosa & Avicel & Amprotab & \\
\hline F I & 10 & 5 & 135 & 0 & 0 & $150 \mathrm{mg}$ \\
F II & 10 & 5 & 0 & 135 & 0 & $150 \mathrm{mg}$ \\
F III & 10 & 5 & 0 & 0 & 135 & $150 \mathrm{mg}$ \\
F IV & 10 & 5 & 67,5 & 67,5 & 0 & $150 \mathrm{mg}$ \\
F V & 10 & 5 & 67,5 & 0 & 67,5 & $150 \mathrm{mg}$ \\
F VI & 10 & 5 & 0 & 67,5 & 67,5 & $150 \mathrm{mg}$ \\
F VII & 10 & 5 & 45 & 45 & 45 & $150 \mathrm{mg}$ \\
\hline
\end{tabular}

Keterangan : tiap formula dibuat tablet dalam 2 batch $(1$ batch $=200$ tablet $)$

\section{Pencampuran}

Masing-masing komponen bahan diayak dengan ayakan mesh 40. Masingmasing bahan ditimbang sesuai dengan formula desain dan dicampur menggunakan cube mixer.

Prednisolone dicampur dengan eksipien Laktosa, Avicel pH-101 dan Amprotab sesuai dengan komposisi bahan pada formula desain hingga homogen dalam cube mixer selama 10 menit dengan kecepatan putar $30 \mathrm{rpm}$.
Ditambahkan $\mathrm{Mg}$ Stearat dicampur selama 2 menit (30 rpm).

\section{Pembuatan Tablet}

Formula tablet prednisolone dimasukan ke dalam ruang cetakan dan dikempa oleh kedua gerakan punch atas dan bawah. Massa tablet dicetak dengan kecepatan putaran mesin $20 \mathrm{rpm}$. Parameter yang dibuat konstan pada pencetakan tablet ini adalah berat total masing-masing tablet $150 \mathrm{mg}$ dan 
kekerasan tablet dikendalikan berada pada kisaran 4- $10 \mathrm{~kg}$.

\section{Uji Sifat Fisik Tablet Prednisolone}

a. Keseragaman Ukuran

Ambil 20 tablet dari masingmasing batch. Diameter tablet dan ketebalan tablet diukur dengan menggunakan jangka sorong. Kecuali dinyatakan lain, diameter tablet tidak lebih dari tiga kali dan tidak kurang dari $1 \frac{1}{3}$ (satu sepertiga) kali tebal tablet (Anonim, 1979).

b. Keseragaman Bobot

Sejumlah 20 tablet yang telah dibersihkan dari debu ditimbang satu per satu, dihitung bobot rata-rata tiap tablet. Jika dihitung satu per satu, tidak boleh lebih dari 2 tablet yang masingmasing bobotnya menyimpang dari bobot rata-ratanya lebih besar dari harga yang ditetapkan pada kolom A. Selain itu, tidak satu tablet pun yang bobotnya menyimpang dari bobot rataratanya lebih dari harga yang ditetapkan kolom B (Anief, 2007).

c. Kekerasan Tablet

Sebuah tablet diletakkan di tengah dan tegak lurus pada hardness tester, mula-mula pada posisi nol, kemudian dengan alat diputar pelanpelan hingga tablet pecah. Dibaca skala yang dicapai pada tablet saat pecah atau hancur (Lachman et al., 1994).

d. Kerapuhan Tablet

Sejumlah 20 tablet dibebasdebukan. Ditimbang dalam neraca analitik yang dinyatakan sebagai $\mathbf{M}_{1}$. Kemudian dimasukkan ke dalam friabilator. Alat dijalankan selama 4 menit dengan kecepatan 25 putaran per menit. Setelah 4 menit atau 100 kali putaran, tablet dikeluarkan dari alat, dibebasdebukan lagi dan ditimbang yang kemudian dinyatakan sebagai $\mathbf{M}_{2}$. Kerapuhan tablet merupakan selisih berat tablet sebelum yang diuji tidak boleh berkurang lebih $1 \%$ dari berat awal tablet awal uji.

Kerapuhan tablet $=\frac{\mathrm{M} 1-\mathrm{M} 2}{\mathrm{M} 1} \times 100 \%$

Keterangan :

$\mathrm{M}_{1}=$ berat tablet mula-mula

$\mathbf{M}_{2}=$ berat tablet setelah perlakuan

(Mohrle, 1989)

e. Waktu Hancur 
Waktu hancur tablet adalah waktu yang diperlukan untuk hancurnya tablet dalam waktu yang sesuai, sehingga tidak ada bagian yang tertinggal diatas kasa (Banker and Anderson, 1986). Waktu hancur untuk tablet tidak bersalut adalah kurang dari 15 menit. Peralatan uji waktu hancur terdiri dari rak keranjang yang mempunyai enam lubang yang terletak vertikal diatas ayakan mesh nomor 10, selama percobaan tablet diletakkan pada tiap lubang keranjang. Kemudian keranjang tersebut bergerak naik turun pada larutan transparan dengan kecepatan 29-32 putaran permenit. Interval waktu hancur adalah 5-30 menit (Ansel, 1989). Disintegrasi terjadi sempurna jika sudah tidak ada partikel tablet (kecuali penyalut) yang masih tertinggal diatas ayakan (Agoes, 2008).

\section{Uji Disolusi}

a. Pembuatan Medium Disolusi

Medium disolusi yang digunakan adalah $1,5 \%$ natrium lauril sulfat dalam cairan lambung tanpa pepsin sebanyak $900 \mathrm{ml}$ yang dimasukkan ke dalam labu disolusi. Cara pembuatannya yaitu dengan menimbang 2,0 $\mathrm{g} \mathrm{NaCl}$, dilarutkan dalam $200 \mathrm{ml}$ aquades, dan ditambahkan $7 \mathrm{ml} \mathrm{HCl}$ 37\%. Larutan diencerkan dengan menambahkan aquades di dalam labu ukur hingga volume 1 liter. Larutan diatur pada $\mathrm{pH}$ 1,2 \pm 0,05 dan ditambahkan 5,0 $\mathrm{g}$ natrium lauril sulfat dalam larutan tersebut (Anonim ${ }^{\mathrm{b}}$, 1995).

b. Uji Disolusi

Uji disolusi dilakukan dengan menggunakan dissolution tester tipe basket. Kecepatan putar pengaduk basket diatur pada kecepatan 50 rpm dengan jarak pengaduk basket dari dasar adalah 2,5 cm. Suhu percobaan dipertahankan berada pada $37-38{ }^{\circ} \mathrm{C}$ (Anonim, 1994). Dilakukan 2 kali replikasi untuk uji disolusi tablet.

c. Pengambilan Sampel

Sampel hasil disolusi tablet prednisolone diambil dari medium disolusi pada menit ke 5, 10, 20, 45, 60, dan 90, masing-masing sebanyak 5,0 mL. Sampel yang diambil kemudian diganti dengan medium disolusi baru dalam jumlah yang sama yaitu 5,0 ml sehingga volume medium disolusi tetap. Dilakukan 2 kali 
replikasi dalam uji ini (Kiran et al., 2010).

Sampel yang telah diperoleh dari menit ke 5, 10, 20, 45, 60, dan 90 diukur absorbansinya pada spektrofotometer UV pada panjang gelombang maksimum piroksikam dalam medium disolusi. Hasil absorbansi yang diperoleh dimasukkan dalam persamaan regresi linier untuk memperoleh konsentrasinya.

d. Penentuan kadar Prednisolone dalam Medium Disolusi

1) Penetapan Panjang Gelombang Maksimum dalam Medium Disolusi

Ditimbang seksama $50 \quad \mathrm{mg}$ prednisolone dan dilarutkan dalam 100 $\mathrm{ml}$ medium disolusi. Larutan tersebut kemudian diencerkan hingga diperoleh konsentrasi $10 \mu \mathrm{g} / \mathrm{ml}$ dengan cara $1 \mathrm{ml}$ larutan diencerkan dalam $50 \mathrm{ml}$ medium disolusi. Larutan dengan konsentrasi 10 $\mu \mathrm{g} / \mathrm{ml}$ dibaca absorbansinya pada panjang gelombang 180-380 nm.

2) Penentuan Kurva Baku Prednisolone dalam Medium Disolusi

Dibuat seri konsentrasi larutan baku dengan cara mengencerkan larutan baku piroksikam $50 \mu \mathrm{g} / 100 \mathrm{ml}$ dalam medium disolusi. Sehingga diperoleh 6 konsentrasi larutan baku yaitu $4 \mu \mathrm{g} / \mathrm{ml}$, $5 \mu \mathrm{g} / \mathrm{ml}, 6 \mu \mathrm{g} / \mathrm{ml}, 7 \mu \mathrm{g} / \mathrm{ml}, 8 \mu \mathrm{g} / \mathrm{ml}$, dan $10 \mu \mathrm{g} / \mathrm{ml}$ yang dibuat dengan cara mengambil larutan dengan konsentrasi $10 \mu \mathrm{g} / \mathrm{ml}$ sebanyak $4 \mathrm{ml}, 5 \mathrm{ml}, 6 \mathrm{ml}, 7$ $\mathrm{ml}, 8 \mathrm{ml}$, dan $10 \mathrm{ml}$ kemudian diencerkan dalam $10 \mathrm{ml}$ medium disolusi. Absorbansi larutan baku dibaca pada panjang gelombang maksimum. Dari hasil pembacaan panjang gelombang maksimum dibuat kurva hubungan absorbansi sebagai fungsi konsentrasi sehingga diperoleh persamaan regresi linier $\mathrm{y}=\mathrm{bx}+\mathrm{a}$.

3) Kadar Prednisolone dalam Sampel Disolusi

Sampel uji disolusi dibaca absorbansinya pada panjang gelombang maksimum sehingga diperoleh absorbansi sampel. Setelah memperoleh nilai absorbansi dari masing-masing formula selanjutnya dihitung mengenai kadar prednisolone dari persamaan garis regresi linier hubungan antara absorbansi dengan kadar prednisolone dalam medium disolusi. Pengungkapan data disolusi pada penelitian ini dilihat melalui nilai konsentrasi pada $\mathrm{t}=45$ menit $\left(\mathrm{C}_{45}\right)$ mengacu pada syarat yang ditetapkan 
dalam USP XXIII yang menyatakan bahwa kadar prednisolone pada tablet piroksikam pada $\mathrm{t}=45$ menit tidak kurang dari $75 \%$.

\section{Uji Keseragaman kadar Tablet Prednisolone}

a. Penetapan Panjang Gelombang Maksimum Prednisolone

Prednisolone ditimbang seksama sebanyak $50 \mathrm{mg}$ dan dilarutkan dalam $100 \mathrm{ml} \mathrm{HCl}-M e t a n o l ~(1: 1200)$. Larutan tersebut kemudian diencerkan hingga diperoleh konsentrasi $10 \mu \mathrm{g} / \mathrm{ml}$ dengan cara $1 \mathrm{ml}$ larutan diencerkan dalam 50 ml HCl-Metanol (1:1200). Larutan dengan konsentrasi $10 \mu \mathrm{g} / \mathrm{ml}$ dibaca absorbansinya pada panjang gelombng 180-380 nm. Secara teoritik prednisolone mempunyai panjang gelombang maksimum $333 \mathrm{~nm}$ (Anonim, 2007).

b. Pembuatan Kurva Baku Prednisolone

Dibuat seri konsentrasi larutan baku dengan cara mengencerkan larutan baku prednisolone $50 \mu \mathrm{g} / 100 \mathrm{ml}$ menggunakan HCl-Metanol (1:1200). Sehingga diperoleh 6 konsentrasi larutan baku yaitu $3 \mu \mathrm{g} / \mathrm{ml}, 4 \mu \mathrm{g} / \mathrm{ml}, 5 \mu \mathrm{g} / \mathrm{ml}, 6 \mu \mathrm{g} / \mathrm{ml}$, $7 \mu \mathrm{g} / \mathrm{ml}$, dan $8 \mu \mathrm{g} / \mathrm{yang}$ dibuat dengan cara mengambil larutan dengan konsentrasi $10 \mu \mathrm{g} / \mathrm{ml}$ sebanyak $3 \mathrm{ml}, 4$ $\mathrm{ml}, 5 \mathrm{ml}, 6 \mathrm{ml}, 7 \mathrm{ml}$, dan $8 \mathrm{ml}$ kemudian diencerkan dalam $10 \mathrm{ml}$ HCl-Metanol (1:1200). Absorbansi larutan baku dibaca pada panjang gelombang maksimum. Dari hasil pembacaan panjang gelombang maksimum dibuat kurva hubungan absorbansi sebagai fungsi konsentrasi sehingga diperoleh persamaan regresi linier $\mathrm{y}=\mathrm{bx}+\mathrm{a}$.

c. Keseragaman kadar dalam Tablet Prednisolone

Satu tablet piroksikam dilarutkan dalam $100 \mathrm{ml}$ HCl-Metanol (1:1200) sehingga diperoleh konsentrasi teoritik $10 \mathrm{mg}$ prednisolone /100 ml. Diambil 1 $\mathrm{ml}$ larutan prednisolone $10 \mathrm{mg} / 100 \mathrm{ml}$ kemudian diencerkan menggunakan HCl-Metanol (1:1200) hingga $10 \mathrm{ml}$, sehingga diperoleh larutan prednisolone dengan konsentrasi teoritik $10 \mu \mathrm{g} / \mathrm{ml}$. Larutan tersebut dibaca absorbansinya pada panjang gelombang maksimum sehingga diperoleh absorbansi sampel. Kadar prednisolone dalam tablet dihitung dengan mengkonversi absorbansi sampel menggunakan persamaan regresi linier kurva baku $\mathrm{y}=\mathrm{bx}+\mathrm{a}$, dengan memperhatikan faktor 
pengenceran. Rumus kadar sediaan tablet Prednisolone yang prednisolone dalam tablet: $\quad$ optimum. Pada penelitian dilakukan $\%$ kadar piroksikam $=$ pencampuran bahan-bahan yang akan

$$
\frac{(\text { Absorbansi-a) }}{\mathrm{b}} \times \frac{\mathrm{fp}}{10} \times 100 \%
$$

\section{( 6 )}

Keterangan :

absorbansi = nilai Y pada

persamaan regresi linier

a = nilai a (intersep) pada persamaan regresi linier

$\mathrm{b}=$ nilai $\mathrm{b}$ (koefisien regresi/slop) pada persamaan regresi linier

$\mathrm{fp}=$ faktor pengenceran

Pengujian dilakukan terhadap 10 tablet dengan cara yang sama. Kemudian dihitung kadar rata-rata prednisolone tiap tablet. Menurut monografi kadar prednisolone tidak kurang dari 97\% dan tidak lebih dari 103\% (Anonim, 2007).

\section{HASIL DAN PEMBAHASAN}

Penelitian ini dilakukan untuk mengetahui pengaruh dan proporsi penggunaan eksipien laktosa, avicel $\mathrm{pH}$ 101 dan amprotab untuk membuat suatu dicetak menjadi tablet, kemudian dilakukan uji sifat fisik tablet berupa keseragaman bobot, keseragaman ukuran, kekerasan, kerapuhan, waktu hancur, serta uji disolusi, dan keseragaman kadar, kemudian dilakukan pemilihan formula optimum tablet prednisolone dengan eksipien laktosa, avicel pH-101 dan amprotab dengan metode Simplex Lattice Design.

\section{A. Pembuatan Tablet Prednisolone}

Pembuatan tablet prednisolone dilakukan dengan metode cetak langsung. Pembuatan tablet dimulai dengan penentuan formula dilakukan menggunakan variasi eksipien yaitu Laktosa (komponen A), Avicel pH-101 (komponen B), dan Amprotab (komponen C) dalam proporsi tertentu. Formula umum untuk tiap tablet (berat total $=150 \mathrm{mg}$ ) adalah seperti yang tercantum pada tabel 


\begin{tabular}{lcccccc}
\hline & \multicolumn{5}{c}{ Bahan (mg) } & Bobot \\
\cline { 2 - 6 } Formula & Prednisolone & $\begin{array}{c}\text { Mg } \\
\text { Stearat }\end{array}$ & Laktosa & Avicel & Amprotab & Tablet \\
\hline F I & 10 & 5 & 135 & 0 & 0 & $150 \mathrm{mg}$ \\
F II & 10 & 5 & 0 & 135 & 0 & $150 \mathrm{mg}$ \\
F III & 10 & 5 & 0 & 0 & 135 & $150 \mathrm{mg}$ \\
F IV & 10 & 5 & 67,5 & 67,5 & 0 & $150 \mathrm{mg}$ \\
F V & 10 & 5 & 67,5 & 0 & 67,5 & $150 \mathrm{mg}$ \\
F VI & 10 & 5 & 0 & 67,5 & 67,5 & $150 \mathrm{mg}$ \\
F VII & 10 & 5 & 45 & 45 & 45 & $150 \mathrm{mg}$ \\
\hline
\end{tabular}

Keterangan : tiap formula dibuat tablet dalam 2 batch $(1$ batch $=200$ tablet $)$

Masing-masing komponen tablet $150 \mathrm{mg}$ dan kekerasan tablet bahan diayak dengan ayakan mesh dikendalikan berada pada kisaran 440. Masing-masing bahan ditimbang $10 \mathrm{~kg}$.

sesuai dengan formula desain dan dicampur menggunakan cube mixer untuk memperoleh campuran yang homogen. Prednisolone selanjutnya dicampur dengan eksipien Laktosa, Avicel pH-101 dan Amprotab sesuai dengan komposisi bahan pada formula desain hingga homogen dalam cube mixer selama 10 menit dengan kecepatan putar $30 \mathrm{rpm}$, kemudian ditambahkan Mg Stearat dicampur selama 2 menit (30 rpm).

Formula tablet Prednisolone dimasukan ke dalam ruang cetakan dan dikempa oleh kedua gerakan punch atas dan bawah. Massa tablet dicetak dengan kecepatan putaran mesin 20 rpm. Parameter yang dibuat konstan pada pencetakan tablet ini adalah berat total masing-masing

\section{B. Hasil Uji Sifat Fisik Tablet}

\section{Prednisolone}

Uji sifat fisik tablet berupa keseragaman bobot, keseragaman ukuran, kekerasan, kerapuhan, waktu hancur, serta uji disolusi, dan keseragaman kadar.

\section{Keseragaman Bobot}

Keseragaman bobot ditunjukkan dengan bobot tablet yang seragam dan sesuai dengan bobot yang dikehendaki. Pengujian terhadap keseragaman bobot perlu dilakukan karena keseragaman bobot menjadi indikator keseragaman kadar/kandungan zat aktif, dengan asumsi bahwa campuran massa yang akan dikempa tercampur secara homogen. Maka ketika 
telah dikempa menjadi tablet jika bobotnya seragam dapat diasumsikan memiliki kadar yang seragam pula (Sulaiman, 2007).

Uji keseragaman bobot dilakukan dengan menimbang 20 tablet prednisolone satu per satu, kemudian dihitung bobot rata-rata tiap tablet lalu dianalisis dengan membandingkan syarat-syarat dalam Farmakope Indonesia yaitu untuk tablet tidak bersalut yang mempunyai bobot rata-rata 150 mg, tidak boleh lebih dari 2 tablet yang masing-masing bobotnya menyimpang dari bobot rata- ratanya lebih besar dari $10 \%$ dan tidak satupun tablet yang bobotnya menyimpang dari bobot rata-ratanya lebih dari $20 \%$ (Anonim, 1979).

Hasil uji keseragaman bobot untuk 7 formula diperoleh hasil yaitu bobot tablet prednisolone mendekati nilai 150 mg dengan nilai $\mathrm{CV}<5 \%$ sesuai dengan persyaratan uji keseragaman bobot. Hasil uji keseragaman bobot tablet piroksikam dapat dilihat pada Tabel 3.

Tabel 3. Hasil uji keseragaman bobot tablet prednisolone dengan kombinasi avicel PH-101

\begin{tabular}{|c|c|}
\hline $\begin{array}{l}\text { Kombinasi Avicel PH- } \\
101\end{array}$ & $\begin{array}{c}\text { Keseragaman } \\
\text { Bobot (mg) }\end{array}$ \\
\hline $100 \%$ Avicel & $149,850 \pm 0,556$ \\
\hline $\begin{array}{l}50 \% \text { Laktosa }+50 \% \\
\text { Avicel }\end{array}$ & $149,960 \pm 0,581$ \\
\hline $\begin{array}{l}50 \% \text { Avicel }+50 \% \\
\text { Amprotab }\end{array}$ & $150,200 \pm 0,808$ \\
\hline $\begin{array}{l}33,3 \% \text { Laktosa }+33,3 \% \\
\text { Avicel }+33,3 \% \text { Amprotab }\end{array}$ & $149,860 \pm 0,758$ \\
\hline $\begin{array}{l}\text { Hasil uji keseragaman } \\
\text { bobot menunjukkan tidak lebih } \\
\text { dari } 2 \text { tablet yang bobotnya } \\
\text { menyimpang dari bobot rata- } \\
\text { ratanya lebih besar dari } 10 \% \\
(135,225-165,275 \mathrm{mg}) \text { dan tidak }\end{array}$ & $\begin{array}{l}\text { satupun tablet yang bobotnya } \\
\text { menyimpang dari bobot rata- } \\
\text { ratanya lebih dari } 20 \% \text { (120,2- } \\
180,3 \mathrm{mg}) \text {, artinya semua formula } \\
\text { tablet memenuhi syarat uji } \\
\text { keseragaman bobot berdasarkan } \\
\text { Farmakope Indonesia. }\end{array}$ \\
\hline
\end{tabular}




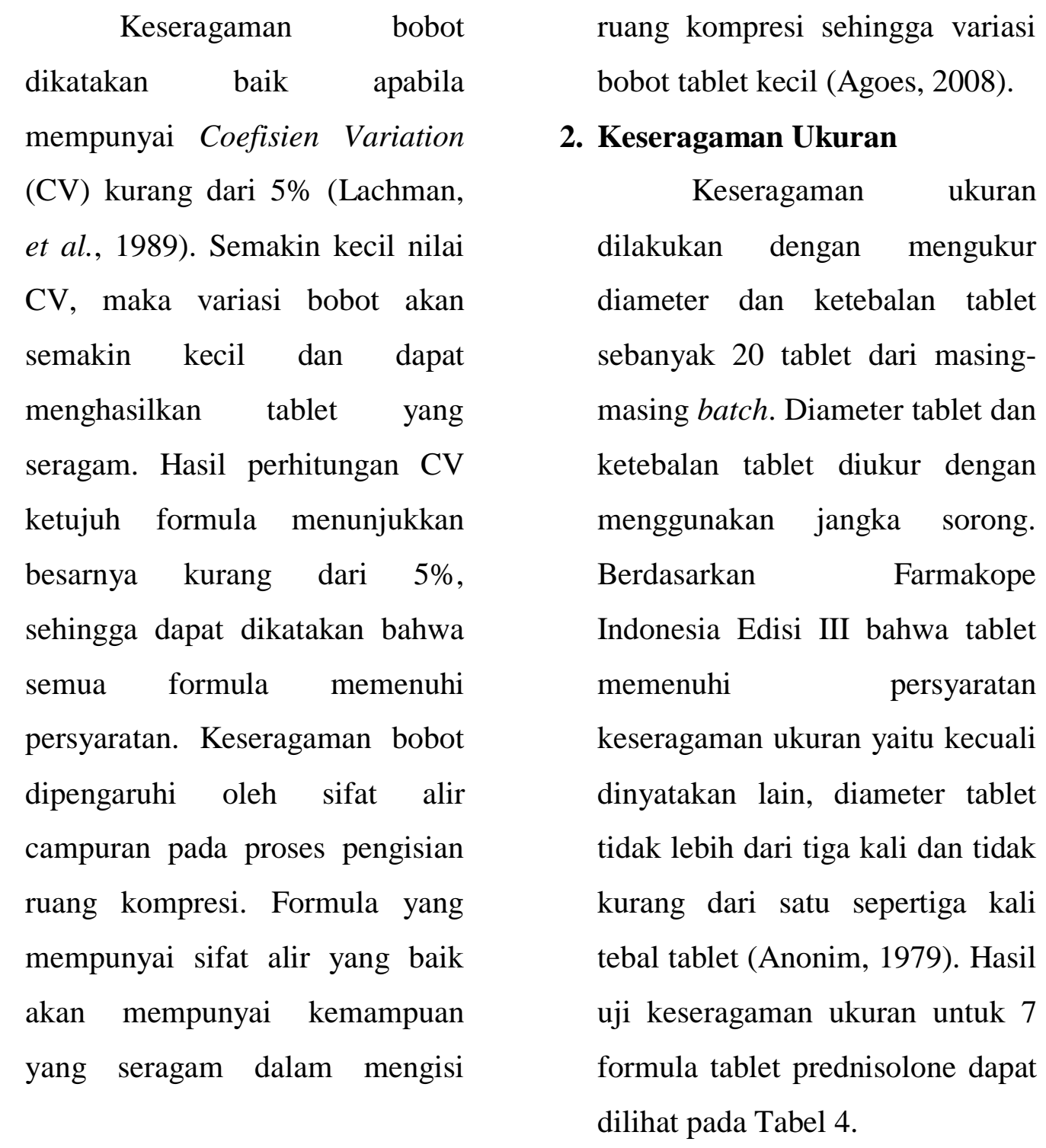

Tabel 4. Hasil uji keseragaman ukuran tablet prednisolone dengan kombinasi laktosa, avicel PH-101, dan amprotab

\begin{tabular}{|c|c|c|c|c|}
\hline \multirow[t]{2}{*}{ Formula } & \multicolumn{2}{|l|}{ Kombinasi } & \multirow{2}{*}{$\begin{array}{l}\text { Ukuran } \\
\text { Diameter Tablet } \\
\text { (cm) }\end{array}$} & \multirow{2}{*}{$\begin{array}{l}\text { Ukuran Tebal } \\
\text { Tablet }(\mathrm{cm})\end{array}$} \\
\hline & $\begin{array}{l}\text { Avicel PH-1 } \\
\text { Amprotab }\end{array}$ & dan & & \\
\hline II & $100 \%$ Avicel & & $0,700 \pm 0,000$ & $0,235 \pm 0,000$ \\
\hline IV & $\begin{array}{l}50 \% \text { Laktosa } \\
\text { Avicel }\end{array}$ & $+50 \%$ & $0,700 \pm 0,000$ & $0,238 \pm 0,004$ \\
\hline VI & $\begin{array}{l}50 \% \text { Avicel } \\
\text { Amprotab }\end{array}$ & $50 \%$ & $0,700 \pm 0,000$ & $0,303 \pm 0,004$ \\
\hline VII & $\begin{array}{l}33,3 \% \text { Laktosa } \\
\text { Avicel + 33,3\% }\end{array}$ & $\begin{array}{l}+33,3 \% \\
\text { Amprotab }\end{array}$ & $0,700 \pm 0,000$ & $0,301 \pm 0,001$ \\
\hline
\end{tabular}


Analisis dari data yang diperoleh menunjukkan bahwa ketujuh formula memenuhi persyaratan uji sifat fisik keseragaman ukuran tebal dan diameter tablet prednisolone karena masih dalam rentang yang diijinkan yaitu diameter tidak boleh lebih dari tiga kali tebal tablet maka diameter tidak boleh lebih dari $0,798 \mathrm{~cm}$ dan tidak boleh kurang dari satu sepertiga tebal tablet maka diameter tidak boleh kurang dari $0,355 \mathrm{~cm}$. Hal tersebut dikarenakan pada pembuatan masing-masing formula tinggi rendahnya punch dan tekanan dari mesin yang konsisten. Selain itu, sifat alir dari formula juga mempengaruhi keseragaman pengisian ruang die. Formula yang memiliki sifat alir baik akan memiliki ukuran tablet yang lebih seragam (Banker dan Anderson, 1994).

\section{Ketebalan} tablet dipengaruhi oleh jumlah bahan yang dapat diisikan ke dalam cetakan dan besarnya tekanan waktu dilakukan kompresi. Pada beban kempa yang konstan, ketebalan tablet bervariasi dengan berubahnya pengisian die, dengan distribusi ukuran partikel serta kepadatan campuran partikel yang dikempa, dan dengan berat tablet, sementara pada keadaan pengisian die yang konstan, ketebalan bervariasi dengan berubahnya beban kompresi (Banker dan Anderson, 1994).

\section{Kekerasan}

Uji kekerasan tablet didefinisikan sebagai uji kekuatan tablet yang mencerminkan kekuatan tablet secara keseluruhan, yang diukur dengan memberikan tekanan terhadap diameter tablet dengan skala kekerasan dalam kilogram $(\mathrm{kg})$ (Sulaiman, 2007). Umumnya semakin besar tekanan semakin keras tablet yang dihasilkan, walaupun sifat dari bahan dan campuran formula juga menentukan kekerasan tablet (Agoes, 2008).

Kekerasan tablet yang baik adalah $4 \mathrm{~kg}$ sampai $10 \mathrm{~kg}$ (Parrott, 1971). Kekerasan berbanding terbalik dengan kerapuhan tablet. Tablet yang memiliki kekerasan 
tinggi berarti ikatan antar partikel kuat, sehingga tidak mudah rusak oleh goncangan. Hal ini berarti bahwa tablet dengan kekerasan yang tinggi memiliki kerapuhan yang rendah (Voight, 1994). Kekerasan yang tinggi juga merupakan salah satu indikator waktu hancur yang lebih lama sehingga berhubungan pula dengan disolusi tablet yang lebih rendah (Agoes, 2008). Hasil uji kekerasan tablet piroksikam dapat dilihat pada Tabel 5 .

Tabel 5.Hasil uji kekerasan tablet prednisolone dengan kombinasi laktosa, avicel PH-101, dan amprotab

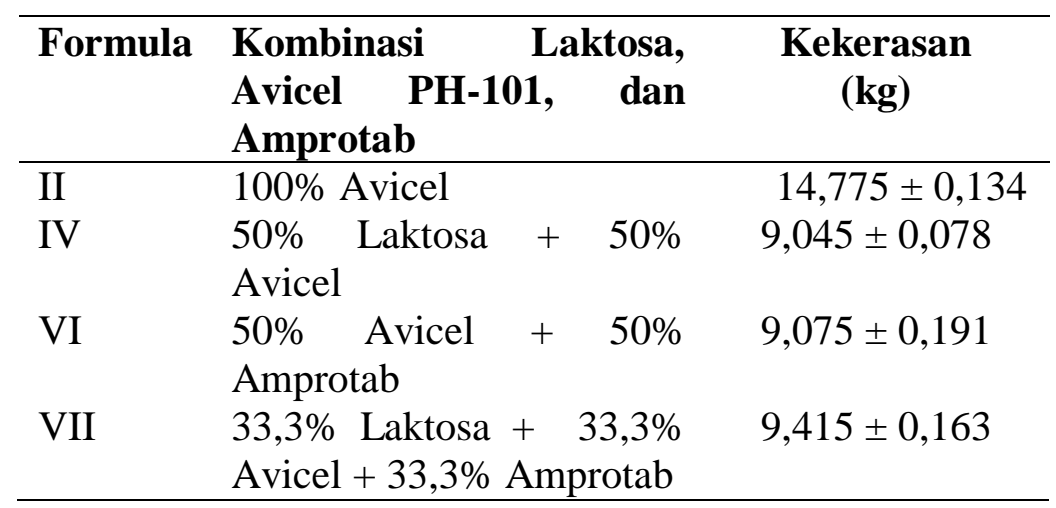

Analisis dari data yang diperoleh menunjukkan bahwa sebanyak 6 formula tablet (F IV, F VI, F VII) memenuhi persyaratan kekerasan tablet yaitu kekerasannya berada dalam rentang 4-10 kg, namun pada F II (100\% Avicel PH-101) memiliki kekerasan yang sangat tinggi yaitu $14,775 \mathrm{~kg}$ dan tidak memenuhi persyaratan uji kekerasan pada Farmakope Indonesia. Hal ini terjadi karena Avicel PH-101 memiliki daya ikat yang kuat dalam campuran untuk membentuk tablet yang keras, sehingga pada komposisi yang besar (lebih dari 70\%), tablet yang menggunakan bahan tambahan ini menjadi terlalu keras (Agoes, 2008).

\section{Kerapuhan}

Kerapuhan tablet menunjukkan ketahanan tablet terhadap abrasi pada permukaan tablet. Batas kerapuhan tablet yang masih bisa diterima adalah kurang dari 1,0\%. Kerapuhan 
diatas $1,0 \%$ menunjukkan tablet yang rapuh dan dianggap kurang baik (Banker dan Anderson, 1986).

Semakin keras tablet yang dibuat maka kerapuhan tablet juga semakin rendah. Semakin besar harga persentase kerapuhan, maka semakin besar massa tablet yang hilang. Hal itu akan mempengaruhi kandungan zat aktif pada tiap tablet. Sifat kohesifitas eksipien yang kuat akan menghasilkan tablet yang keras, dengan kerapuhan yang kecil. Selain kohesifitas, pengisian ruang die, pada saat pengempaan berlangsung akan mempengaruhi kekompakan dan kekerasan tablet yang dihasilkan sehingga tablet yang dihasilkan lebih kompak dan akan mengurangi kerapuhannya (Agoes, 2008). Hasil uji kerapuhan tablet prednisolone dapat dilihat pada Tabel 6 .

Tabel 6.Hasil uji kerapuhan tablet prednisolone dengan kombinasi laktosa, avicel PH-101, dan amprotab

\begin{tabular}{|c|c|c|c|c|}
\hline Formula & Kombinasi & & tosa, & Kerapuhan (\%) \\
\hline & $\begin{array}{l}\text { Avicel PH-1 } \\
\text { Amprotab }\end{array}$ & & dan & \\
\hline II & $100 \%$ Avicel & & & $0,002 \pm 0,002$ \\
\hline IV & $\begin{array}{l}50 \% \text { Laktosa } \\
\text { Avicel }\end{array}$ & + & $50 \%$ & $0,076 \pm 0,030$ \\
\hline VI & $\begin{array}{l}50 \% \text { Avicel } \\
\text { Amprotab }\end{array}$ & + & $50 \%$ & $0,034 \pm 0,027$ \\
\hline VII & $\begin{array}{l}33,3 \% \text { Laktosa } \\
\text { Avicel + 33,3\% }\end{array}$ & & $\begin{array}{l}3,3 \% \\
\text { otab }\end{array}$ & $0,059 \pm 0,048$ \\
\hline
\end{tabular}

Analisis dari data yang diperoleh menunjukkan bahwa tablet pada ketujuh formula memenuhi persyaratan kerapuhan tablet yaitu kehilangan bobot tidak lebih dari 1\%. Persamaan untuk kerapuhan dapat diperoleh menurut pendekatan $S L D$ yaitu :

\section{Waktu Hancur}

Waktu hancur merupakan waktu yang dibutuhkan untuk hancurnya tablet menjadi partikelpartikel penyusunnya bila kontak dengan cairan. Waktu hancur tablet akan mempengaruhi profil disolusi dan kadar obat yang 
diabsorpsi pada suatu tablet. Untuk siap diabsorpsi harus dalam keadaan terlarut, supaya obat mudah larut maka tablet harus berada dalam bentuk partikel atau granul. Waktu hancur untuk tablet tidak bersalut adalah kurang dari 15 menit (Banker dan Anderson, 1994). Hasil uji waktu hancur tablet piroksikam dapat dilihat pada Tabel 7.

Tabel 7.Hasil uji waktu hancur tablet prednisolone dengan kombinasi laktosa, avicel PH-101, dan amprotab

\begin{tabular}{llrlrl}
\hline Formula & $\begin{array}{l}\text { Kombinasi } \\
\text { Avicel PH-101, dan } \\
\text { Amprotab }\end{array}$ & $\begin{array}{l}\text { Laktosa, } \\
\text { (menit) }\end{array}$ & \\
\hline II & 100\% Avicel & 19,525 & \pm & 0,968 \\
IV & $50 \%$ Laktosa + 50\% Avicel & 11,304 & \pm & 0,252 \\
VI & $50 \%$ Avicel + 50\% & 1,396 & \pm & 0,075 \\
& Amprotab & & & \\
VII & $33,3 \%$ Laktosa + 33,3\% & $1,075 \pm 0,083$ \\
& Avicel + 33,3\% Amprotab & & & \\
\hline
\end{tabular}

Analisis dari data yang diperoleh menunjukkan bahwa sebanyak 6 formula tablet (F IV, F VI, F VII) memenuhi persyaratan waktu hancur tablet yaitu kurang dari 15 menit, namun pada F II (100\% Avicel PH-101) memiliki waktu hancur rata-rata 19,525 menit sehingga tidak memenuhi persyaratan uji waktu hancur berdasarkan Farmakope Indonesia.

\section{Disolusi}

Disolusi adalah proses suatu bahan kimia atau obat menjadi terlarut dalam suatu pelarut. Laju disolusi adalah kecepatan perubahan bentuk padat menjadi bentuk terlarut dalam mediumnya setiap waktu tertentu yang dapat mempengaruhi kecepatan dan jumlah obat yang diabsorpsi (Martin et al., 1993). Pada disolusi, kekerasan mempengaruhi pelepasan prednisolone dari tablet. Tablet yang semakin keras menyebabkan pori-pori tablet akan semakin kecil. Hal ini menyebabkan penetrasi pelarut akan lebih sulit 
untuk melakukan pembasahan sehingga proses pengembangan dan pelarutan prednisolone dalam tablet akan lebih lambat (Banker dan Anderson, 1994).

Sampel disolusi yang telah diambil dalam waktu tertentu diukur absorbansinya pada panjang gelombang 334,5 $\mathrm{nm}$. Kadar prednisolone dalam sampel disolusi dihitung dengan mengkonversi absorbansi sampel menggunakan persamaan regresi linier kurva baku $\mathrm{y}=0,0859 \mathrm{x}-$ 0,0934. Nilai $\mathrm{x}$ yang didapat adalah nilai kadar prednisolone yang terdapat dalam sampel disolusi. Kemudian dibuat dalam nilai persentase kadar piroksikam yang terdisolusi dengan rumus :

$$
\% \text { zat terdisolusi }=\frac{\text { nilai } X}{\text { kadar rata }- \text { rata }} \times 100 \%
$$

Berikut ini adalah persentase zat terlarut yang didapat dari hasil perhitungan:

Tabel 8. Persentase Kadar Prednisolone terlarut/terdisolusi

\begin{tabular}{ccccccc}
\hline \multirow{2}{*}{ Formula } & \multicolumn{6}{c}{ Kadar Pada menit ke- (\%) } \\
\cline { 2 - 7 } & $\mathbf{5}^{\prime}$ & $\mathbf{1 0}^{\prime}$ & $\mathbf{2 0}$ & $\mathbf{4 5}^{\prime}$ & $\mathbf{6 0}$ & $\mathbf{9 0}$ \\
\hline II & 11,11 & 19,47 & 38,00 & 64,07 & 78,39 & 90,50 \\
\hline IV & 44,33 & 72,97 & 97,42 & 100,21 & 100,44 & 100,91 \\
\hline VI & 89,80 & 98,77 & 100,63 & 101,33 & 101,56 & 101,56 \\
\hline VII & 96,90 & 97,49 & 100,75 & 100,91 & 101,61 & 101,84 \\
\hline
\end{tabular}

Tabel diatas menunjukkan $\mathrm{mg}$ atau $75 \%$ mengacu pada syarat kadar prednisolone dalam sampel yang ditetapkan dalam USP XXIII. pada menit ke-45 yang dinamakan Formula 2 tidak memenuhi metode Wagner. Metode ini persyaratan karena nilai $\mathrm{Ct}_{45}$ formula menunjukkan jumlah zat aktif yang 2 adalah $64,07 \%$, hal ini dipengaruhi terlarut pada waktu t (Siregar, 2008). karena kekerasan yang tinggi Pada penelitian ini digunakan $\mathrm{Ct}_{45}$ sehingga tablet dengan eksipien $100 \%$ artinya jumlah zat aktif telah larut avicel ini sulit mengembang dan dalam waktu 45 menit sebanyak 7,5 
hancur, sehingga tablet yang diperoleh sukar terlarut.

Grafik profil disolusi tablet prednisolone dapat dilihat pada gambar 14.

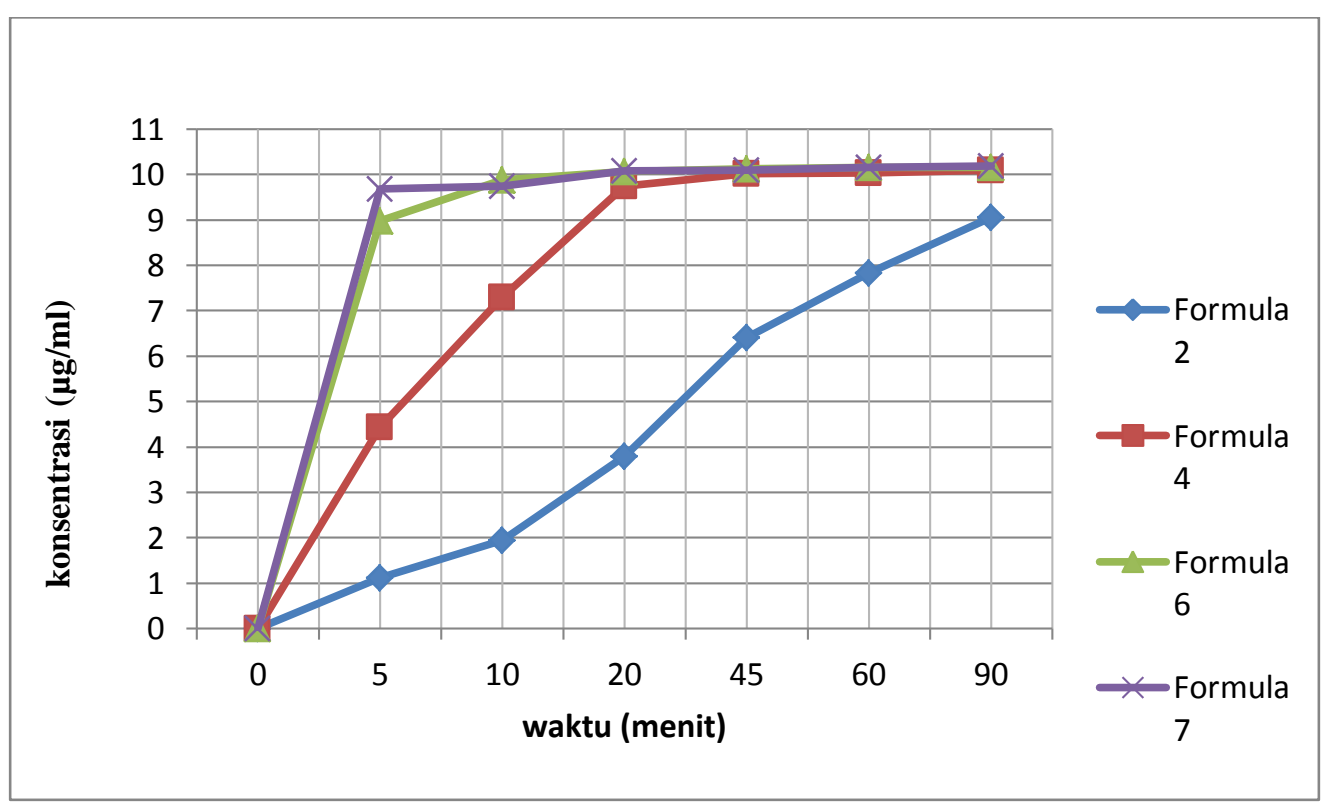

Gambar 14. Grafik profil disolusi tablet prednisolone

Nilai $\mathrm{Ct}_{45}$ hasil uji disolusi tablet piroksikam dapat dilihat pada Tabel 9.

Tabel 9. Nilai $\mathrm{Ct}_{45}$ hasil uji disolusi tablet prednisolone dengan kombinasi laktosa, avicel PH-101, dan amprotab

\begin{tabular}{|c|c|c|c|c|}
\hline Formula & Kombinasi & Laktosa, & Kadar & Persen kadar \\
\hline & $\begin{array}{l}\text { Avicel PH-101 } \\
\text { Amprotab }\end{array}$ & 1, dan & $\begin{array}{l}\text { Prednisolone } \\
\text { Terlarut (mg) }\end{array}$ & $(\%)$ \\
\hline II & $100 \%$ Avicel & & $6,407 \pm 0,061$ & 64,07 \\
\hline IV & $\begin{array}{l}50 \% \text { Laktosa } \\
\text { Avicel }\end{array}$ & $+50 \%$ & $10,021 \pm 0,184$ & 100,21 \\
\hline VI & $\begin{array}{l}50 \% \text { Avicel } \\
\text { Amprotab }\end{array}$ & $+50 \%$ & $10,133 \pm 0,014$ & 101,33 \\
\hline VII & $\begin{array}{l}\text { 33,3\% Laktosa + } \\
\text { Avicel }+ \\
\text { Amprotab }\end{array}$ & $\begin{array}{r}33,3 \% \\
33,3 \%\end{array}$ & $10,091 \pm 0,024$ & 100,91 \\
\hline
\end{tabular}
tablet dari masing-masing formula

\section{Keseragaman Kadar}

Pengujian keseragaman kadar merupakan versi kuantitatif dari pengujian identifikasi tablet. Satu digerus, dan zat aktif dalam tablet dilarutkan menggunakan pelarut $\mathrm{HCl}-$ Metanol (1:1200). Meskipun spesifikasi untuk hasil penentuan 
berbeda dari satu produk terhadap sepuluh tablet di uji satu persatu produk lainnya, umumnya rentang kadarnya dengan melarutkannya pada kadar bahan aktif yang ditentukan metanol-HCL dalam $100 \mathrm{ml}$. berada diantara 97-103\% (Anonim, kemudian diencerkan 20 kali hingga 2007). mendapat konsentrasi $5 \mu \mathrm{g} / \mathrm{ml}$, lalu

Keseragaman kadar dalam dibaca absorbansinya pada panjang tablet dilakukan untuk memastikan gelombang maksimal yaitu 332,0 nm. keseragaman potensi dari tablet Kemudian dihitung persentasi kadar berdosis rendah seperti piroksikam piroksikam dalam tablet dengan dengan dosis $10 \mathrm{mg}$. sejumlah rumus :

$$
\% \text { kadar prednisolone }=\frac{(\text { Absorbansi }-\mathrm{a})}{\mathrm{b}} \times \frac{\mathrm{fp}}{10} \times 100 \%
$$

Keterangan :

absorbansi $=$ nilai $Y$ pada persamaan regresi linier

a = nilai a (intersep) pada persamaan regresi linier

$\mathrm{b}=$ nilai $\mathrm{b}$ (koefisien regresi/slop) pada persamaan regresi linier

$\mathrm{fp} \quad=$ faktor pengenceran $(20 \mathrm{x})$

$10=$ kadar teoritik prednisolone $(10 \mathrm{mg})$

Tabel 10. Hasil uji keseragaman kadar tablet prednisolone dengan kombinasi laktosa, avicel PH-101, dan amprotab

\begin{tabular}{|c|c|c|c|c|}
\hline \multirow[t]{2}{*}{ Formula } & Kombinasi & Laktosa, & \multirow{2}{*}{$\begin{array}{l}\text { Kadar } \\
\text { Prednisolone } \\
\text { (mg) }\end{array}$} & \multirow{2}{*}{$\begin{array}{c}\text { Persen kadar } \\
(\%)\end{array}$} \\
\hline & $\begin{array}{l}\text { Avicel PH-101, } \\
\text { Amprotab }\end{array}$ & 1, dan & & \\
\hline II & $100 \%$ Avicel & & $9,939 \pm 0,059$ & 99,39 \\
\hline IV & $\begin{array}{l}50 \% \text { Laktosa } \\
\text { Avicel }\end{array}$ & $+50 \%$ & $9,917 \pm 0,122$ & 99,17 \\
\hline VI & $\begin{array}{l}50 \% \text { Avicel } \\
\text { Amprotab }\end{array}$ & $+50 \%$ & $9,943 \pm 0,101$ & 99,43 \\
\hline VII & $\begin{array}{l}33,3 \% \text { Laktosa + } \\
\text { Avicel }+ \\
\text { Amprotab }\end{array}$ & $\begin{array}{l}33,3 \% \\
33,3 \%\end{array}$ & $10,079 \pm 0,030$ & 100,79 \\
\hline
\end{tabular}

\section{KESIMPULAN}

Interaksi kedua komponen avicel PH-

101 dan amprotab merupakan faktor yang paling dominan dalam menurunkan kerapuhan tablet. Interaksi ketiga komponen laktosa, 
avicel PH-101, dan amprotab merupakan faktor yang paling dominan dalam menurunkan $\mathrm{CV}$ keseragaman bobot, meningkatkan keseragaman bobot, meningkatkan

\section{SARAN}

Perlu dilakukan uji validasi dari area optimum dengan menggunakan satu titik pada area optimum formula tablet prednisolone dengan kombinasi eksipien Laktosa, Avicel PH-101, dan Amprotab.

\section{DAFTAR PUSTAKA}

Agoes, G, 2008, Pengembangan Sediaan Farmasi, Penerbit ITB, Bandung, hal: 287-299.

Anief, M., 2007, Farmasetika, 94-96, Universitas Gadjah Mada Press, Yogyakarta.

Anonim, 1979, Farmakope Indonesia, Edisi III, 7-8, Departemen Kesehatan Republik Indonesia, Jakarta.

Anonim ${ }^{\mathrm{a}}$, 1995, Farmakope Indonesia, edisi IV, Departemen Kesehatan Republik Indonesia, Jakarta hal: 108, 488, 683.

Anonim $^{\mathrm{b}}$, 1995, The United States Pharmacopeia, 23 rd Ed,1375, The US Pharmacopeial Convention Inc, Twinbook Parkway, Rockville.

Ansel, H. C., 1989, Pengantar Bentuk Sediaan Farmasi, Edisi IV, 154,
257-259, 261-263, 271-273, 399405, Universitas Indonesia Press, Jakarta.

Ansel, H.C., Allen,L.V., dan Popovich, N.G., 1999, Capsul and Tablets dalam Pharmaceutical Dosage and Drug Delivery System, Lippincott Williams and Wilkin, New York, pp: 208-218, 229-235.

Banker, G.S., dan Anderson, N.R., 1986, Tablet, in Lachman L., Lieberman, H.A., Kanig, J.L. (eds), The Theory and Practice of Industrial Pharmacy, 643-705, terjemahan Siti Suyatmi, Edisi ke-3, Julid II, Universitas Indonesia Press, Jakarta.

Bolton, S., 1997, Pharmaceutical Statistics : Practical and Clinical Aplication, Edisi III, Marcell Dekker Inc., New York, pp : 591-610, 1025-1038.

Carter, J.C., 2006, The Role of Lubricants in Solid Oral Dosage Manufacturing, Pharm. Article, Carter Parmaceutical Inc.,

http://www.carterpharmaceuticalcons ulting.com/articles/The-role-ofdisintergrants.html., Diakses tanggal 24 November 2017.

Gunsel, W.C., dan Kanig, J.L. 1976, Tablet in Lachman L., Lieberman, H.A., Kanig, J.L. (eds), The Theory and Practice of Industrial Pharmacy, 2nd Ed., 321-358, Leaand Febiger, Philadelpia.

Harjunen, P., Lehto, V., Martimo, K., Suihko, E., Lankinen, T., Paronen, P., Jarvinen, K., 2002, Lactose Modification Enhance its Drug Performance in The Novel Multiple Dose Taifun® 
DPI, Eur.J.Pharm.Sci., 16 (4-5), 313.

Helene, R. 2003, Uniformity of Multi Unit Tablets Under Pilot Plant Conditions as a Function of Unit Size and Filler Composition, Umi Tubugen, Eberharld Korls, 48-49.

Ikawati, Zullies. 2015. Farmakologi Molekuler.Universitas Gadjah Mada. Yogyakarta.

Jones, D., 2008, PharmaceuticsDosage Form and Design, 210, 212, 214-216, 218, Pharmaceutical Press, London.

Katzung, B.G., Farmakologi Dasar dan Klinik ed.VI, UI Press, Jakarta, hal : 567.

Kurniawan, D.W., dan Sulaiman, T.N.S., 2009, Teknologi Sediaan Farmasi, 92-97, Graha Ilmu, Yogyakarta.

Lachman, L., Lieberman, H.A., dan Kanig, J.L., 1994, Teori dan Praktek Farmasi Industri, diterjemahkan oleh Siti Suyatmi, Iis Arsyah, Edisi III, 686, 699- 700-701, 705, UI Press, Jakarta.

Parrott, E.L., 1971, Pharmaceutical Technology

Fundamental Pharmaceutics, 3rd Ed, 73-82 Burgers Publishing Company, Minneapols.

Rowe, R. C, Sheskey, P., Owen, S., 2006, Handbook of Pharmaceutical Excipients $4^{\text {th }}$ Ed., 430, 611-612, 767, Pharmaceutical Press and
American Pharmacist

Association, America.

Sheth, B.B., Bandelin, F.J., and Shangraw , R.F., 1980, Compressed table, in Pharmaceutical Dosage Form : Tablets, Vol.I, by Lachman and Lieberman, 109-184, Marcell Dekker Inc., New York.

Siregar, Charles J.P., 2008, Teknologi Farmasi Sediaan Tablet : DasarDasar Praktis, Jakarta: Penerbit Buku Kedokteran, EGC, Hal. 90, 98110

Voight, R., 1994, Buku Pelajaran Teknologi Farmasi, Diterjemahkan oleh Soendani Noerono Soewandhi, Edisi ke-5, Cetakan kedua, 163-224, Universitas Gadjah Mada Press, Yogyakarta. 